\title{
Psychosocial treatments of behavior symptoms in dementia: a systematic review of reports meeting quality standards
}

\author{
Daniel W. O'Connor, ${ }^{1}$ David Ames, ${ }^{2}$ Betina Gardner ${ }^{1}$ and Madeleine King ${ }^{3}$ \\ ${ }^{1}$ Department of Psychological Medicine, Monash University, Melbourne, Australia \\ ${ }^{2}$ National Ageing Research Institute, University of Melbourne, Melbourne, Australia \\ ${ }^{3}$ Centre for Health Economics Research and Evaluation, University of Technology, Sydney, Australia
}

ABSTRACT

Objective: To provide a systematic review of selected experimental studies of psychosocial treatments of behavioral disturbances in dementia. Psychosocial treatments are defined here as strategies derived from one of three psychologically oriented paradigms (learning theory, unmet needs and altered stress thresholds).

Method: English language reports published or in press by December 2006 were identified by means of database searches, checks of previous reviews and contact with recognized experts. Papers were appraised with respect to study design, participants' characteristics and reporting details. Because people with dementia often respond positively to personal contact, studies were included only if control conditions entailed similar levels of social attention or if one treatment was compared with another.

Results: Only 25 of 118 relevant studies met every specification. Treatment proved more effective than an attention control condition in reducing behavioral symptoms in only 11 of the 25 studies. Effect sizes were mostly small or moderate. Treatments with moderate or large effect sizes included aromatherapy, abilityfocused carer education, bed baths, preferred music and muscle relaxation training.

Conclusions: Some psychosocial interventions appear to have specific therapeutic properties, over and above those due to the benefits of participating in a clinical trial. Their effects were mostly small to moderate with a short duration of action. This limited action means that treatments will work best in specific, timelimited situations. In the few studies that addressed within-group differences, there were marked variations in response. Some participants benefited greatly from a treatment, while others did not. Interventions proved more effective when tailored to individuals' preferences.

Key words: dementia, behavior, treatment, evidence, systematic review

\section{Introduction}

Dementia is often complicated by agitation, aggression, disinhibition and other challenging behaviors. In a British survey, aggression was reported by the carers of $4 \%$ of persons with mild dementia, $14 \%$ of those with moderate dementia and $42 \%$ of those with severe dementia (O'Connor et al., 1990). The number and severity of behavioral changes correlate strongly with carer burden (O'Connor et al., 1990) and thus with admission to aged residential facilities (Haupt and Kurz, 1993) where rates of such behaviors are typically high. Cohen-Mansfield (1986), for example, found that

Correspondence should be addressed to: Professor Daniel O'Connor, Aged Mental Health Research Unit, Kingston Centre, Warrigal Road, Cheltenham, Victoria 3192, Australia. Phone: +61 (03) 92651700 Fax: +61 (03) 9265 1711. Email: daniel.oconnor@med.monash.edu.au. Received: 15 January 2008; revision requested: 27 February 2008; revised version received: 23 April 2008; accepted: 30 April 2008. First published online 25 September 2008.
$24 \%$ of the residents of a large North American nursing home hit, kicked or threw things each day.

Antidepressant, antipsychotic and analgesic medications can be effective when behaviors stem from co-morbid major depression, delusions or pain. In remaining cases, antipsychotic medications are preferred by most psychogeriatricians (Greve and O'Connor, 2005) but concerns have been raised about their efficacy and safety (Schneider et al., 2006). Alternative approaches that seek to relieve behavioral symptoms by means of social, psychological and nursing interventions warrant serious scientific scrutiny.

Previous reviewers agreed that studies of socalled psychosocial treatments are often too small, loosely designed and poorly reported to warrant clear conclusions (Opie et al., 1999; CohenMansfield, 2001; Livingston et al., 2005). To counter this, only papers that met specified quality 
standards are outlined here with the object of guiding clinicians and carers to robustly supported evidence.

\section{Treatment paradigms}

Three broad, psychologically-oriented paradigms have emerged to explain changed behaviors in dementia and to generate testable interventions to limit their frequency, severity and practical consequences.

Learning theory asserts that behaviors are reinforced when carers reward them with attention. Calling out, for example, increases in frequency if staff members attend to nursing home residents when they are noisy but ignore them at other times. The $A B C$ model (Antecedents, Behaviors, Consequences) seeks to reinforce appropriate behaviors and discourage dysfunctional ones (Teri et al., 1998).

In the unmet needs paradigm, inappropriate behaviors stem from normal human needs physical, emotional and social - that carers fail to perceive or address (Cohen-Mansfield, 2001). These needs encompass meaningful activity, pleasurable social interaction and freedom from pain. Strategies to address them include recreation, physical exercise and adequate analgesia to name just a few.

According to the stress threshold model, dementia reduces the capacity to cope with stress, resulting in inappropriate behaviors (Hall and Buckwalter, 1987). Stress levels can be modulated to tolerable levels by attending to signals of distress and alternating periods of rest and activity.

Most psychosocial treatments blend elements of all three paradigms. Attendance at a music therapy session in a nursing home, for example, might result in (i) positive interaction with staff, thus reinforcing attentive, appropriate behavior; (ii) an opportunity to engage in pleasing, creative activity, and (iii) release from the meaningless, anxiety-provoking commotion of a communal living area.

This review addresses three questions: (i) Are the benefits of psychosocial treatments just the result of the care and attention that follow from participation in a clinical trial? (ii) Do treatments reduce the frequency and/or severity of behavioral symptoms to a degree that matters to patients, families and caregivers? and (iii) Does one treatment work better than another?

\section{Methods}

This review was compiled in line with Australian National Health and Medical Research Council recommendations (NH\&MRC, 2000a). English language reports published or in press by December 2006 of experimental studies of treatments of challenging behaviors in dementia that were derived from one or more psychologically oriented paradigm were sought via: (i) searches of Medline, CINAHL, PsycInfo and Cochrane databases, (ii) checks of references in earlier reviews and monographs, and (iii) approaches to nearly 60 researchers who had published in this area in recent years. Treatments with a pharmacological, physiological or environmental focus (e.g. psychotropic medications, light therapy and modifications to premises to prevent exiting) fell outside our psychosocial parameter and are reviewed elsewhere (Sink et al., 2005; Opie et al., 1999; Cohen-Mansfield, 2001).

Reviews of many dozens of papers of variable quality have limited value. To make this paper as useful as possible to psychiatrists, psychologists, nurses and diversional therapists, we developed a process to select papers of higher than average quality. Research quality checklists typically look for adequate numbers of participants with low dropout rates; detailed descriptions of participants, interventions and controls; reliable and valid outcome measures; suitable randomization and blinding techniques; control of confounding variables, and appropriate statistical analysis (NH\&MRC, 2000b; Altman et al., 2001). These criteria are designed with drug trials in mind and do not translate easily to procedural treatments where randomized controlled trials (RCTs) are often unaffordable, blinding is impracticable, and retention is compromised by participants' advanced age and physical frailty (Cohen-Mansfield, 2001). Some accommodation of the reality of aged care research is therefore justified.

Well-conducted RCTs form the "gold standard" of clinical trials but other designs warrant inclusion too. As an example, "before and after" or repeated measures (RM) studies, in which all participants receive treatment and act as their own controls, are efficient, robust and equitable, especially when treatment and control conditions are allocated randomly and participants are crossed later from one condition to the other. The potential contamination of RM designs by learning effects, treatment "carry over" and disease progression are unlikely to be a problem in short-term, non-pharmacological trials in people with marked dementia.

Inclusion criteria for this overview balanced scientific rigor with clinical relevance. Given the focus on cognition and behavior, it made sense to require that all study participants had both dementia and significant behavioral symptoms, or seemed likely to have them by virtue of residence in a "special care" dementia unit or psychogeriatric 
Table 1. Process of selecting studies for review

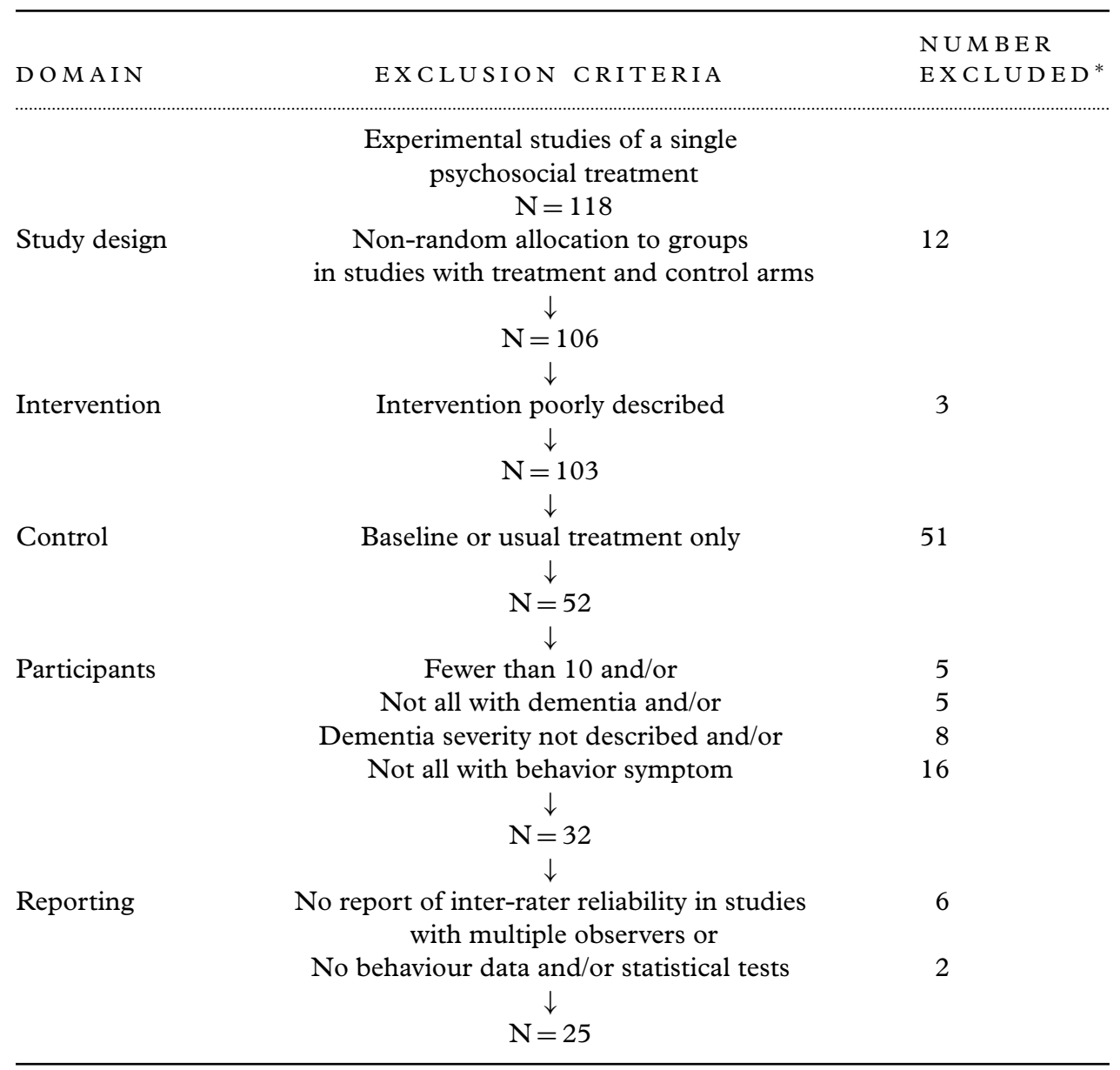

*Some studies were excluded for more than one reason.

ward. "Treating" people with no behavioral symptoms cannot demonstrate improvement if there is nothing to improve.

Secondly, studies were included only if a treatment was compared with another treatment and/or an "attention control" condition. Life in many nursing homes is so unstimulating that personal attention of any kind relieves anxiety and agitation (Garland et al, 2007). Once a study begins, fresh faces appear in the nursing home; residents are offered new activities, and their behavior is monitored more intently than usual. Staff or family caregivers who relish involvement with researchers might also rate dementia symptoms more harshly or leniently, depending on their bias. These placebo effects are powerful. Agitation responded so well to real, and even simulated, personal contact in studies by Cohen-Mansfield and Werner (1997) and Garland et al. (2007) that controlling for nonspecific treatment effects is now desirable. Control conditions should provide equivalent attention and diversion. Examples of attention controls include a general activity session to control for multi-sensory stimulation or a conventional bath to control for one accompanied by music.

Other requirements, adapted from standard research checklists (e.g. Altman et al., 2001), comprised (i) random allocation in the case of studies with distinct treatment and control arms; (ii) sufficient information about a study's methods to permit replication; (iii) a total of 10 or more participants; (iv) the use of cognitive and behaviour measures, and (v) some statistical analysis.

Finally, given the importance of minimizing observer bias, we stipulated that behavior measures must have been collected by persons blinded either to treatment allocation or to the study's aims or, when the nature of the intervention rendered blinding impracticable, that behavior measures were generated (i) by a single individual, e.g. a family caregiver, or (ii) by multiple individuals with high inter-rater reliability, or (iii) through the use of mechanical or electronic counters.

Only 25 papers met every prerequisite. The most common reason for exclusion was lack of an attention control condition (Table 1). A list of 
excluded papers, together with reasons, is available from the authors on request.

Most of our requirements were straightforward. Only a couple required much judgment (e.g. the adequacy of information regarding methodology) but, to reduce concerns of reviewer bias, $24(20 \%)$ of the 118 seemingly eligible papers were coded on the nine key selection criteria listed in Table 1 by a second blinded reviewer. Agreement rates were very high at $92.6 \%$.

As an additional check on quality, papers were graded using a checklist described by Forbes (1998) in an earlier systematic review of behavioral treatments in dementia. The scale addresses study design, participation and retention rates, measurement issues and statistical analysis, and has an algorithm to generate ratings of "strong," "moderate," "weak" and "poor." It follows standard pathways but, in contrast to other scales, it makes allowance for repeated measure designs and the use of non-blinded observers. Only RCTs can qualify as "strong."

Effect sizes based on mean differences and standard deviations were calculated for studies that reported sufficient information (Rosnow and Rosenthal, 1996). For randomized studies, the effect size was the difference between the treatment mean and the attention control mean divided by an estimate of standard deviation pooled from both groups. Baseline means were incorporated if available. We considered an effect size of 0.2 to be small, 0.5 moderate and 0.8 large (Cohen, 1988).

\section{Results}

Of the 25 selected papers, 22 had been published within the last decade. There were 16 from the U.S.A., six from the U.K. and one each from Australia, Canada and Sweden. Nineteen were based solely in nursing homes or long-stay hospital wards. Ten were either RCTs or nested RCTs in which nursing homes (rather than residents) were randomized, and 15 used RM (before and after) designs. All but two of the $15 \mathrm{RM}$ studies added crossover between arms to maximize validity and efficiency. Repeated measures studies with randomized cross-over are labeled here as randomized cross-over trials (RXT). Participant numbers were typically small (mean 46.2, range 13-136).

Primary interventions in descending order of frequency were music (8), carer education (4), sensory enrichment (3), simulated family presence (3), novel bathing techniques (2), aromatherapy (2), recreation (1), relaxation (1) and validation therapy (1). Additional details are provided in Table 2. It so happened that no papers on pet therapy, physical exercise, reality orientation, reminiscence therapy or low stimulus environments met our specifications and we can make no further comment on them. This is a regrettable but anticipated consequence of our selective process. Massage was used as a control condition in a study of music (Remington, 2002).

Using the Forbes quality rating scale (Forbes, 1998), six of the 25 studies were rated as "strong", 16 as "moderate", three as "weak" and none as "poor." All three "weak" studies lost points because of high attrition rates (Cohen-Mansfield and Werner, 1997; Toseland et al., 1997; Teri et al., 2000). Details are presented below. Standards varied nonetheless. Only 14 reports specified the number of persons screened for possible inclusion; 14 listed numbers of drop-outs; five provided a power analysis; 10 included statistical adjustments for possible confounding variables, and three specified ways of handling missing data.

In the interests of uniformity, results are presented wherever possible as the percentage change in behavior symptoms. Treatments proved more effective than attention control conditions, to a statistically significant degree, in only 11 of the 25 studies. Among these 11, effect sizes could be computed only for nine. They were mostly small to moderate with large effects just for bed baths versus tub baths (Dunn et al., 2002) and preferred music versus "classical relaxation" music (Gerdner, 2000) (Table 2).

\section{Aromatherapy}

Oils extracted from the plants Lavendula angustifolia (lavender) and Melissa officinalis (lemon balm) have been thought for centuries to have soothing properties. To test this, Holmes et al. (2002) sprayed the communal area of a dementia ward with either $2 \%$ lavender oil or water for two hours daily on alternating days. All 15 participants had severe dementia and daily agitation. An observer wearing a nose clip rated behaviors using the Pittsburgh Agitation Scale in the final hour of 10 sessions. Median behavior scores were $20 \%$ lower while exposed to lavender compared to water $(\mathrm{p}=0.016)$.

In a nested RCT by Ballard et al. (2002), 71 severely demented nursing home residents with clinically significant agitation were massaged lightly on the face and arms with either lemon balm or sunflower oil for one to two minutes twice daily for four weeks. Blinded observers completed the Cohen-Mansfield Agitation Inventory (CMAI) before and after this period. Scores on the CMAI fell by $35 \%$ on average in the Melissa group versus $11 \%$ for sunflower oil $(\mathrm{p}<0.0001)$. There were 
Table 2. Details of selected studies

\begin{tabular}{|c|c|c|c|c|c|c|c|c|c|}
\hline $\begin{array}{l}\text { AUTHOR (S)/ } \\
\text { YEAR }\end{array}$ & $\begin{array}{l}\text { TREATMENT } \\
(\mathrm{T})\end{array}$ & $\begin{array}{l}\text { AT TENTION } \\
\text { CONTROL } \\
\text { (AC) }\end{array}$ & $\mathrm{N}$ & $\begin{array}{l}\text { STUDY } \\
\text { DESIGN }\end{array}$ & $\begin{array}{l}\text { STUDY } \\
\text { LENGTH } \\
\text { (WKS) }\end{array}$ & $\begin{array}{l}\text { O BSERVATION } \\
\text { TIMING }\end{array}$ & $\begin{array}{l}\text { BEHAVIOR } \\
\text { MEASURE }\end{array}$ & $\begin{array}{l}\text { QUALITY } \\
\text { RATING }\end{array}$ & $\begin{array}{l}\text { STATISTICAL } \\
\text { RESULTS, } \\
\text { EFFECT SIZE } \\
\text { (ES) }\end{array}$ \\
\hline \multicolumn{10}{|l|}{ Aroma } \\
\hline $\begin{array}{l}\text { Ballard et al. } \\
\quad(2002)\end{array}$ & Melissa oil & Neutral oil & 71 & $\begin{array}{l}\text { Nested RCT, } \\
\text { blinded } \\
\text { observers }\end{array}$ & 4 & $\begin{array}{l}\text { Study start and } \\
\text { end }\end{array}$ & CMAI & 4 & $\begin{array}{l}\mathrm{T}>\mathrm{AC}^{* * *} \\
\quad(\mathrm{ES}=0.71)\end{array}$ \\
\hline $\begin{array}{l}\text { Holmes et al. } \\
\quad \text { (2002) }\end{array}$ & Lavender vapor & Water vapor & 15 & $\begin{array}{l}\text { RXT, blinded } \\
\text { observers }\end{array}$ & 2 & $\begin{array}{l}\text { During } \\
\text { intervention }\end{array}$ & PAS & 3 & $\begin{array}{l}\mathrm{T}>\mathrm{AC}^{*} \\
\quad(\mathrm{ES}=0.57)\end{array}$ \\
\hline \multicolumn{10}{|l|}{ Bathing } \\
\hline $\begin{array}{l}\text { Dunn et al. } \\
\quad(2002)\end{array}$ & Bed bath & Tub bath & 15 & $\begin{array}{l}\mathrm{RXT} \\
\quad \mathrm{IRR}=96 \%\end{array}$ & 8 & $\begin{array}{l}\text { During } \\
\text { intervention }\end{array}$ & $\begin{array}{l}\text { Direct } \\
\text { observation } \\
\text { (CMAI) }\end{array}$ & 3 & $\begin{array}{l}\mathrm{T}>\mathrm{AC}^{* * *} \\
\quad(\mathrm{ES}=1.15)\end{array}$ \\
\hline $\begin{array}{l}\text { Sloane et al. } \\
\quad(2004)\end{array}$ & $\begin{array}{l}\text { Person-centered } \\
\text { bed bath }\end{array}$ & $\begin{array}{l}\text { Person-centered } \\
\text { shower }\end{array}$ & 69 & $\begin{array}{l}\text { RXT, blinded } \\
\text { observers }\end{array}$ & 12 & $\begin{array}{l}\text { During } \\
\text { intervention }\end{array}$ & $\begin{array}{l}\text { Direct } \\
\text { observation } \\
\text { (CMAI) }\end{array}$ & 4 & $\begin{array}{c}\mathrm{T}=\mathrm{AC} \mathrm{T}>\mathrm{BL}^{* *} \\
\mathrm{AC}>\mathrm{BL}^{*}\end{array}$ \\
\hline \multicolumn{10}{|l|}{ Carer education } \\
\hline $\begin{array}{l}\text { Burgio et al. } \\
\quad(2002)\end{array}$ & $\begin{array}{l}\text { Behavior } \\
\text { management } \\
\text { training with } \\
\text { continued } \\
\text { supervision }\end{array}$ & $\begin{array}{l}\text { Behavior } \\
\text { management } \\
\text { training without } \\
\text { continued } \\
\text { supervision }\end{array}$ & 79 & $\begin{array}{l}\text { Nested RCT, } \\
\quad \mathrm{IRR}=74 \%\end{array}$ & 26 & $\begin{array}{l}\text { During } \\
\text { intervention }\end{array}$ & $\begin{array}{l}\text { Direct } \\
\text { observation }\end{array}$ & 4 & $\mathrm{~T}=\mathrm{AC}$ \\
\hline $\begin{array}{l}\text { Gormley et al. } \\
\quad(2001)\end{array}$ & $\begin{array}{l}\text { Behavior } \\
\text { management } \\
\text { training }\end{array}$ & Discussion groups & 62 & $\begin{array}{l}\text { RCT, blinded } \\
\text { observers }\end{array}$ & 8 & $\begin{array}{l}\text { Study start and } \\
\text { end }\end{array}$ & RAGE & 4 & $\mathrm{~T}=\mathrm{AC}$ \\
\hline Teri et al. (2000) & $\begin{array}{l}\text { (a) Behavior } \\
\text { management } \\
\text { training, } \\
\text { (b) Haloperidol, } \\
\text { (c) Trazodone }\end{array}$ & & 148 & $\begin{array}{r}\text { RCT, IRR } \\
\text { checked }\end{array}$ & 16 & $\begin{array}{l}\text { Study start and } \\
\text { end }\end{array}$ & CGIC & 2 & $\mathrm{Ta}=\mathrm{Tb}=\mathrm{Tc}$ \\
\hline $\begin{array}{l}\text { Wells et al. } \\
\text { (2000) }\end{array}$ & $\begin{array}{l}\text { Ability-focused } \\
\text { morning care }\end{array}$ & $\begin{array}{l}\text { Usual morning } \\
\text { care }\end{array}$ & 40 & $\begin{array}{r}\text { Nested RCT, } \\
\text { IRR } r>0.7\end{array}$ & 26 & $\begin{array}{l}\text { During } \\
\text { intervention }\end{array}$ & PAS & 3 & $\begin{array}{l}\mathrm{T}>\mathrm{AC}^{*} \\
\quad(\mathrm{ES}=0.62)\end{array}$ \\
\hline
\end{tabular}


Table 2. Continued.

\begin{tabular}{|c|c|c|c|c|c|c|c|c|c|}
\hline $\begin{array}{l}\text { A U THOR (S)/ } \\
\text { YEAR }\end{array}$ & $\begin{array}{l}\text { TREAT MEN T } \\
(\mathrm{T})\end{array}$ & $\begin{array}{l}\text { AT TENTION } \\
\text { CONTROL } \\
\text { (AC) }\end{array}$ & $\mathrm{N}$ & $\begin{array}{l}\text { STUDY } \\
\text { DESIGN }\end{array}$ & $\begin{array}{l}\text { STUDY } \\
\text { LENGTH } \\
\text { (WKS) }\end{array}$ & $\begin{array}{l}\text { OBSERVATION } \\
\text { TIMING }\end{array}$ & $\begin{array}{l}\text { BEHAVIOR } \\
\text { MEASURE }\end{array}$ & $\begin{array}{l}\text { QUA LITY } \\
\text { RATING }\end{array}$ & $\begin{array}{l}\text { STATISTICAL } \\
\text { RESULTS, } \\
\text { EFFECT SIZE } \\
\text { (ES) }\end{array}$ \\
\hline \multicolumn{10}{|l|}{ Music/sound } \\
\hline $\begin{array}{l}\text { Burgio et al. } \\
\quad(1996)\end{array}$ & Natural sounds & $\begin{array}{l}\text { Headphone } \\
\text { only }\end{array}$ & 13 & $\begin{array}{c}\text { RXT, IRR } \\
\quad \kappa>0.7\end{array}$ & 3 & $\begin{array}{l}\text { During } \\
\text { intervention }\end{array}$ & $\begin{array}{l}\text { Direct } \\
\quad \text { observation }\end{array}$ & 3 & $\begin{array}{l}\mathrm{T}>\mathrm{AC}^{* * *} \\
\quad(\mathrm{ES}=0.27)\end{array}$ \\
\hline $\begin{array}{l}\text { Clark et al. } \\
\quad(1998)\end{array}$ & $\begin{array}{l}\text { Preferred music } \\
\text { during bath }\end{array}$ & Usual bath & 18 & $\begin{array}{l}\text { RXT, IRR } \\
\quad r>0.9\end{array}$ & 4 & $\begin{array}{l}\text { During } \\
\text { intervention }\end{array}$ & $\begin{array}{l}\text { Direct } \\
\text { observation }\end{array}$ & 3 & $\begin{array}{l}\mathrm{T}>\mathrm{AC}^{*} \\
\quad(\mathrm{ES}=0.47)\end{array}$ \\
\hline Gerdner (2000) & Preferred music & Classical music & 39 & $\begin{array}{l}\mathrm{RXT}, \\
\quad \mathrm{IRR}=93 \%\end{array}$ & 17 & $\begin{array}{l}\text { During, after } \\
\text { intervention }\end{array}$ & $\begin{array}{l}\text { Direct } \\
\quad \text { observation }\end{array}$ & 3 & $\begin{array}{l}\mathrm{T}>\mathrm{AC}^{* * *} \\
\quad(\mathrm{ES}=1.19)\end{array}$ \\
\hline Groene (1993) & Music therapy & Reading & 30 & $\begin{array}{l}\text { RCT, counting } \\
\text { devices }\end{array}$ & 1 & $\begin{array}{l}\text { During } \\
\text { intervention }\end{array}$ & $\begin{array}{l}\text { Direct } \\
\text { observation }\end{array}$ & 3 & $\mathrm{~T}=\mathrm{AC}$ \\
\hline $\begin{array}{l}\text { Ragneskog et al. } \\
\text { (1996) }\end{array}$ & $\begin{array}{l}\text { Music during } \\
\text { meal time }\end{array}$ & Usual mealtime & 20 & $\begin{array}{l}\text { RXT, blinded } \\
\text { observer }\end{array}$ & 7 & After intervention & GBS & 3 & $\mathrm{~T}=\mathrm{AC}$ \\
\hline $\begin{array}{l}\text { Remington } \\
\text { (2002) }\end{array}$ & Baroque music & Hand massage & 68 & $\begin{array}{c}\text { RCT, IRR } \\
\quad r>0.9\end{array}$ & $<1$ & $\begin{array}{l}\text { During, after } \\
\text { intervention }\end{array}$ & $\begin{array}{l}\text { Direct } \\
\quad \text { observation }\end{array}$ & 3 & $\begin{array}{l}\mathrm{T}=\mathrm{AC} \\
\mathrm{T}, \mathrm{AC}>\mathrm{BL}^{* *}\end{array}$ \\
\hline $\begin{array}{l}\text { Sherratt et al. } \\
\quad(2004)\end{array}$ & $\begin{array}{l}\text { (a) Live music } \\
\text { (b) Recorded } \\
\text { music }\end{array}$ & $\begin{array}{l}\text { Commercial } \\
\text { music }\end{array}$ & 24 & $\begin{array}{r}\mathrm{RM}, \mathrm{IRR} \\
\kappa>0.6\end{array}$ & 1 & $\begin{array}{l}\text { During } \\
\text { intervention }\end{array}$ & $\begin{array}{l}\text { Direct } \\
\text { observation }\end{array}$ & 3 & $\mathrm{Ta}, \mathrm{Tb}=\mathrm{AC}$ \\
\hline $\begin{array}{l}\text { Thomas et al. } \\
\text { (1997) }\end{array}$ & $\begin{array}{l}\text { Preferred music } \\
\text { during bathing }\end{array}$ & Usual bath & 14 & $\begin{array}{l}\text { RM, IRR } \\
\text { checked }\end{array}$ & 2 & $\begin{array}{l}\text { During } \\
\text { intervention }\end{array}$ & $\begin{array}{l}\text { Direct } \\
\text { observation }\end{array}$ & 3 & $\begin{array}{c}\mathrm{T}>\mathrm{AC}^{*}(\mathrm{ES} \text { not } \\
\text { computable })\end{array}$ \\
\hline \multicolumn{10}{|c|}{ Sensory enrichment } \\
\hline $\begin{array}{l}\text { Baillon et al. } \\
\quad(2004)\end{array}$ & $\begin{array}{l}\text { Multi-sensory } \\
\text { stimulation }\end{array}$ & $\begin{array}{l}\text { Reminiscence } \\
\text { therapy }\end{array}$ & 20 & $\begin{array}{l}\mathrm{RXT}, \mathrm{IRR} \\
\quad r>0.9\end{array}$ & 5 & $\begin{array}{l}\text { During, after } \\
\text { intervention }\end{array}$ & $\begin{array}{l}\text { Direct } \\
\text { observation } \\
\text { (CMAI) }\end{array}$ & 3 & $\mathrm{~T}=\mathrm{AC}$ \\
\hline $\begin{array}{l}\text { Baker et al. } \\
\quad(2003)\end{array}$ & $\begin{array}{l}\text { Multi-sensory } \\
\text { stimulation }\end{array}$ & Activity session & 127 & $\begin{array}{c}\text { RCT IRR } \\
r>0.6\end{array}$ & 4 & $\begin{array}{l}\text { During, after } \\
\text { intervention, } 1 \\
\text { month later }\end{array}$ & Interact & 4 & $\mathrm{~T}=\mathrm{AC}$ \\
\hline $\begin{array}{l}\text { Cohen- } \\
\text { Mansfield } \\
\text { and Werner } \\
\text { (1998) }\end{array}$ & $\begin{array}{l}\text { Enriched } \\
\text { corridor }\end{array}$ & Usual corridor & 27 & $\begin{array}{l}\text { RXT, counting } \\
\text { devices }\end{array}$ & 4 & $\begin{array}{l}\text { During } \\
\text { intervention }\end{array}$ & $\begin{array}{l}\text { Direct } \\
\text { observation }\end{array}$ & 3 & $\mathrm{~T}=\mathrm{AC}$ \\
\hline \multicolumn{10}{|c|}{ Simulated presence } \\
\hline $\begin{array}{l}\text { Camberg et al. } \\
\text { (1999) }\end{array}$ & Family audiotape & $\begin{array}{l}\text { Neutral } \\
\quad \text { audiotape }\end{array}$ & 54 & $\begin{array}{l}\text { RXT, blinded } \\
\text { observers }\end{array}$ & 10 & $\begin{array}{l}\text { During } \\
\text { intervention }\end{array}$ & $\begin{array}{l}\text { Direct } \\
\text { observation }\end{array}$ & 3 & $\mathrm{~T}, \mathrm{AC}=\mathrm{BL}$ \\
\hline
\end{tabular}




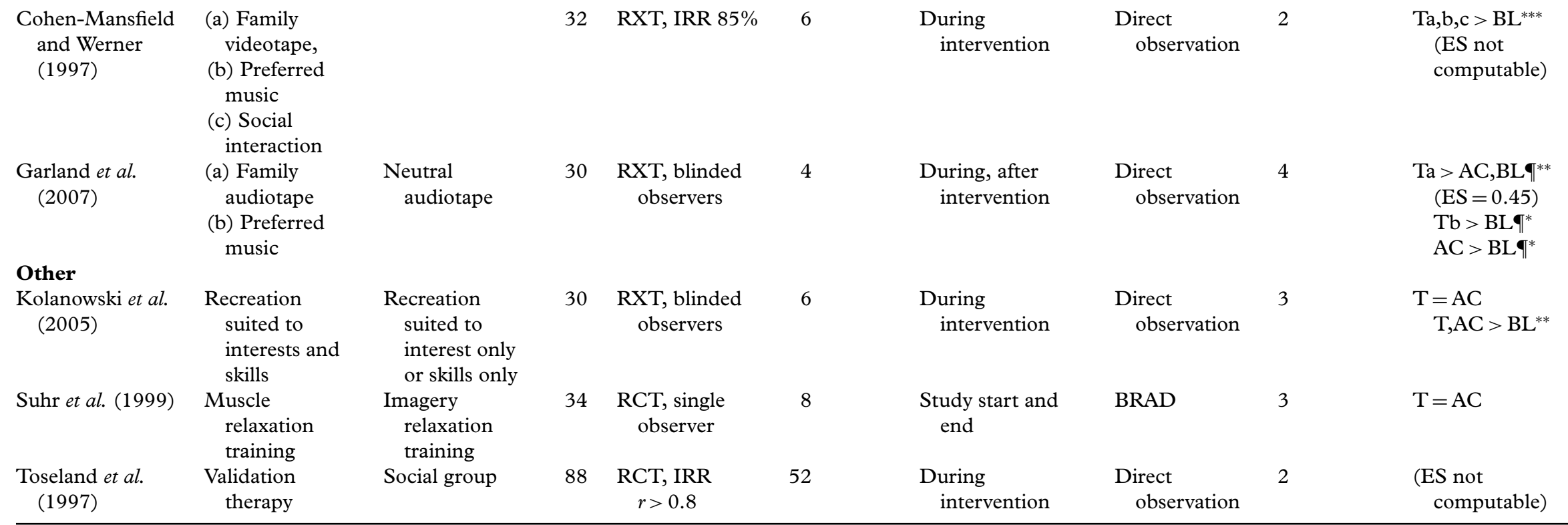

$\mathrm{RCT}=$ randomized controlled trial, $\mathrm{RM}=$ repeated measures, $\mathrm{RXT}=$ repeated measures with randomized cross-over.

$\mathrm{IRR}=$ inter-rater reliability, $r=$ correlation coefficient, $\kappa=$ kappa.

Quality ratings $4=$ strong, $3=$ moderate, $2=$ weak.

$\mathrm{AC}=$ attention control, $\mathrm{BL}=$ baseline/usual care.
${ }^{*} \mathrm{p}<0.05,{ }^{* *} \mathrm{p}<0.01, * * \mathrm{p}<0.001, \mathrm{NS}=$ not significant

q $=$ physical agitation only. 
positive changes too in social engagement and constructive activity.

\section{Bathing}

Bathing routines are potent triggers of agitation and aggression, presumably due to physical discomfort, fear and embarrassment. Bed baths, in which residents are washed in their own bed using heated cloths steeped in a non-rinse skin cleanser, provide an attractive alternative. Dunn et al. (2002) compared four conventional tub baths with four bed baths in a repeated measures study of 15 dementia unit residents. Trained observers counted every occurrence of 14 specified agitated behaviors from the moment of undressing to bath completion. Mean total behavior counts were $50 \%$ lower during bed baths than conventional ones $(p<0.001)$.

Sloane et al. (2004) scrutinized what processes underlie this improvement by means of a repeated measures study in which the staff of 10 nursing homes were trained in "person-centred" bathing. This entailed meeting residents' preferences, minimizing discomfort, and speaking calmly. Bed baths as described already were then compared in a cross-over design with conventional showers over a 12 -week period. Another five homes acted as "usual-care" controls. Baths were videotaped for each of the 69 agitated, aggressive residents and their behaviors were counted by trained observers blind to the study's aims. Rates of agitation and aggression fell significantly in both person-centered conditions (showering $32 \%$, bed bath $37 \%$ ), versus $8 \%$ in usual care $(\mathrm{p}<0.02)$, but neither condition was better than the other. In other respects, bed baths caused less discomfort, took no more time and removed as many skin debris and pathogenic bacteria as showers.

\section{Carer education}

Disruptive behaviors arise in a social context. If people with dementia react negatively to wellintentioned help, caregivers' responses can either soothe or inflame their distress. It makes sense, therefore, to show carers how dementia changes behavior and how to shape constructive responses.

In the first of two studies with family carers, Gormley et al. (2001) randomized 62 community aged psychiatry patients with at least mild aggressive symptoms to either four home-based behavior management training sessions or general discussions of carer-related issues. The training sessions addressed behavior symptoms, precipitating and perpetuating factors, and personalized interventions. Management plans were monitored and refined as required over an eight-week period when a blinded researcher repeated the Rating Scale for Aggressive Behavior in the Elderly (RAGE) in discussion with carers. Scores on RAGE fell by $27 \%$ from baseline in the experimental group versus $2 \%$ for controls $(p=0.07)$. This trend to improvement escaped statistical significance.

In an RCT with 148 people with Alzheimer's disease and at least weekly agitation, Teri et al. (2000) compared the effects of 11 comprehensive behavior training sessions for family caregivers with an antipsychotic medication (haloperidol, mean final dose $1.8 \mathrm{mg}$ daily), a sedating antidepressant (trazodone, mean final dose $200 \mathrm{mg}$ daily) and a placebo tablet. When checked 16 weeks later, the attrition rate was high (39\%) due to adverse effects in the haloperidol arm and to increased agitation in both the behavior management and trazodone arms. For remaining participants, positive outcomes on the Clinical Global Impression of Change (CGIC) rating scale were almost identical (behavior management $32 \%$, haloperidol $32 \%$, trazodone $41 \%$, placebo $31 \%$ ).

Two studies, both nested RCTs, examined the effect of providing additional training to nursing home staff. Burgio et al. (2002) trained 85 care assistants in communication and behavior management skills over a four-week period using a variety of techniques. All of the 79 residents had behavioral disturbances, at least to a mild degree. Staff in half the units then received intensive, continuing supervision with clinical monitoring, verbal and written feedback, and performance incentives to ensure that skills were maintained. The rest were monitored as usual by senior nurses. At six-month followup, the intensive supervision group showed superior skill retention. Agitated behaviors declined in both groups with no significant difference between them.

More encouraging findings emerged when Wells et al. (2000) trained 16 staff members in dementia care, functional assessment, and the use of interventions designed to maintain abilities, and compensate for lost ones, during morning bathing, grooming and dressing. Teaching was reinforced in fortnightly then monthly updates. The 28 care assistants in other units served as controls in this six-month study of 40 "cognitive support" unit residents. On final review, residents in the experimental group showed better function and their caregivers were more resident-focused and relaxed in their approach. Scores on the Pittsburgh Agitation Scale fell by $51 \%$ compared with an increase of $14 \%$ for controls $(p=0.02)$.

\section{Music and sound}

Music has proved a popular subject of research, accounting for a third of the reports selected for review. Topics of interest include the effectiveness 
of soothing sounds; the role of music in specific situations (dining and bathing); comparisons of music with reading and massage, and the relative benefits of different types of music and modes of delivery.

Burgio et al. (1996) measured the responses of 13 severely verbally disruptive nursing home residents to soothing audiotapes of a mountain stream or gentle ocean waves. In their four-week, repeated measures study, tapes were switched on and off at five minute intervals for periods of 20 minutes over a series of eight trials. Not all residents completed every trial. The headphones were refused on $14 \%$ of occasions and eight of the 13 residents (62\%) refused them at least once. Despite this, observed periods free of verbal disruption were significantly lower $(p<0.001)$ when tapes were "on" $(48 \%)$ compared to "off" (42\%). Stream and wave sounds proved equally effective.

Three studies concerned the benefits of music in particular settings. Ragneskog et al. (1996) played three types of music (soft melodious tunes, 1930s jazz and modern pop songs) for two weeks each while 20 residents of a psychogeriatric nursing home ward ate their dinner. When a blinded researcher monitored behavior immediately afterwards using a Scandinavian psychiatric scale (GBS), ratings of restlessness declined by $75 \%$ with soothing music, $33 \%$ with 1930 s jazz and $25 \%$ with modern pop songs. These differences were not statistically significant. Staff served more food while music was playing and residents ate a little more.

In one of two repeated measures studies of bathing, Clark et al. (1998) observed 18 resistive nursing home residents being bathed on 10 occasions while tapes of their preferred music played in the background. When compared with 10 control baths, instances fell by $64 \%$ for yelling, $35 \%$ for grabbing and $27 \%$ for hitting. Rates of all observed aggressive behaviors were halved $(\mathrm{p}<0.05)$. In similar vein, Thomas et al. (1997) observed the responses of 14 resistant nursing home residents, all of whom had been interested in music premorbidly, to bathing with and without preferred music. Counts of physical aggression fell $42 \%$ more during music conditions than controls $(\mathrm{p}<0.05)$. Rates of other behavior types were barely altered.

Another two reports compared music with other therapies. Groene (1993) conducted an RCT in which 30 nursing home residents who wandered were assigned to five, 15-minute sessions of either one-on-one music therapy or readings of material tailored to residents' interests. Motor behavior was monitored by means of videotape, pedometers and electronic counters. Residents stayed closer to therapists while music played but were no less mobile. In the second report, Remington
(2002) assigned 68 agitated nursing home residents to single, brief treatments of calming music (an audiotape of a soft, repetitive baroque classic), gentle hand massage, or a combination of the two. When agitated behaviors were counted during treatments by trained observers, mean agitation counts fell from baseline by $50 \%$ with music tapes, $37 \%$ with massage and $61 \%$ with both. These differences were all statistically significant $(\mathrm{p}<0.01)$ but no treatment worked better than another.

To test the importance in music therapy of personal engagement and interaction, Sherratt et al. (2004) contrasted the responses of a mixed community and residential group of 24 people with challenging behaviors to single, one hour, group exposures to (i) an audiotape of commercially recorded music; (ii) the same music pre-recorded by a musician, and (iii) a live performance by the same musician who sought to engage participants in the activity. The music was broadly in line with participants' preferred styles. While rates of arousal, engagement and well-being were highest when music was played live $(\mathrm{p}<0.01)$, and rates of meaningless behavior and sleep were lowest $(\mathrm{p}<0.01)$, counts by trained observers of wandering and other target behaviors were similar across all conditions.

Finally, Gerdner (2000) counted the behaviors of 39 agitated nursing home residents during and immediately after exposure to either soothing "classical relaxation music" or music that was carefully matched to their interests. In a 12-week, repeated measures study in which audiotaped music was played for 30-minute periods twice weekly at times of peak agitation, rates of agitated behaviors fell from baseline by $49 \%$ during classical music and $61 \%$ during individualized music. Specially chosen music proved superior to "off the shelf" music during the intervention and even 30 minutes later $(\mathrm{p}<0.0001)$.

\section{Sensory enrichment}

Multi-sensory stimulation (MSS, formerly known as Snoezelen) aims to counter the tedium endemic in residential facilities by means of visual, auditory, olfactory and tactile stimuli that participants help generate themselves in a warm, trusting atmosphere with an attendant carer. A typical MSS room provides taped music, aroma, bubble tubes, fiberoptic sprays and moving shapes projected across walls. Baker et al. (2003) compared eight, 30minute MSS sessions with directed activities like card games and quizzes. When 127 moderately or severely demented day care attendees and residents of psychogeriatric wards were randomly assigned to one or other condition, neither treatment 
changed staff ratings of behavior during or after treatment.

Baillon et al. (2004) contrasted MSS with reminiscence therapy, both of which confer supportive one-to-one contact. In a small repeated measures study set in a day-care center and mental health nursing home, 20 participants were exposed to three, 40-minute sessions of one and then the other treatment. Behaviors were rated on the CMAI before, during and after treatments. No differences in levels of agitation emerged, though some participants clearly responded positively to both treatments.

Cohen-Mansfield and Werner (1998) took a different approach. Speculating that much pacing behavior stemmed from bland, institutional surroundings, they assessed the impact of enriched environments on levels of pacing, trespassing and exitseeking in nursing home residents. Two corridors were chosen as the best setting since wanderers spent much of their time there. A "nature scene" was created using posters, plants, forest smells and taped birdsong. A "home and people scene" included family photographs, traditional music and a citrus aroma. Residents' behavior was measured using direct observation, photoelectric counters and activity monitors. The scenarios were inexpensive to construct and led to the 27 residents, all of whom paced or wandered regularly, spending twice more time in the corridors than before $(p<0.01)$. Time spent seated rose significantly in one hallway but not the other, and both trespassing and exit-seeking behaviors fell, though not to a statistically significant degree. Staff and relatives enjoyed the improved environment.

\section{Simulated family presence}

Visits to nursing homes by family members provide comfort in stressful situations but are quickly forgotten by people with dementia. Simulated family presence therapy seeks to fill this void by having relatives make audiotapes of scripted "telephone conversations" about cherished memories from earlier life. The scripts tap remote memory, one of residents' few remaining strengths, and are edited to maximize response.

Camberg et al. (1999) used a repeated measures design to compare simulated presence audiotapes with recorded readings from a newspaper. Staff played the tapes in random order via headphones at least twice daily at times when the 54 selected nursing home residents were either agitated or socially withdrawn. Researchers then monitored behaviors over a four-week period for each condition, but not necessarily while tapes were playing. Despite setbacks (tapes were played inconsistently by staff and behaviors arose less frequently than expected), some participants responded well. Taken overall, though, there were no differences in observed behaviors between the treatment, placebo and usual care conditions.

In a study by Garland et al. (2007), 15-minute simulated presence audiotapes were compared with tapes of music tailored to residents' former interests and a placebo condition of readings from a gardening book. Treatments were applied by blinded researchers over three days each in randomly ordered blocks at times when the 30 nursing home residents were most agitated. For physically agitated behaviors, rates fell by $30 \%$ from baseline during simulated presence $(p=0.003)$, $25 \%$ during personalized music $(\mathrm{p}=0.04)$ and $15 \%$ during placebo. For verbally agitated behaviors, rates fell by $33 \%$ from baseline during simulated presence $(p=0.04), 18 \%$ during music and $29 \%$ during placebo $(\mathrm{p}=0.03)$. Both physical and verbal behavior counts were still lower than baseline 15 minutes later. Roughly half the participants showed a fall in behavior counts of $50 \%$ or more during one or other condition. A few became more disturbed. Recounting positive memories proved burdensome for many family members. Music tapes were easier to prepare and worked almost as well as simulated presence.

Finally, Cohen-Mansfield and Werner (1997) compared simulated presence videotapes with audiotapes of preferred music and one-to-one interaction in a repeated measures study of 32 nursing home residents, all of whom exhibited verbally disruptive behaviors (shouting, complaining, repeating words, etc.). Each of the 30-minute treatments was applied daily for two weeks in varying orders, at times when participants were actively vocalizing. Family members chose the content and style of the simulated presence tapes themselves. In the one-to-one interaction sessions, a research assistant followed broad guidelines (conversation, gentle exercise, a "sensory kit" and manual activities) shaped by participants' abilities and interests. Only 53\% of participants completed all treatments: others died, became quiet or refused the interventions. In those remaining, all three treatments worked better than none $(p<0.001)$. Rates of shouting, for example, fell from baseline by $66 \%$ during one-toone interaction, $50 \%$ during simulated presence and $34 \%$ during preferred music. Four of seven specific behaviors responded best to social interaction; two responded best to simulated presence, and one to music. Behaviors reverted quickly to baseline levels once treatments stopped. It was noted that carefully constructed one-to-one social interaction had a restorative effect on two mute participants 
who started to speak again after a couple of sessions.

\section{Other treatments}

The remaining studies concerned recreation, relaxation training and validation therapy. Kolanowski et al. (2005) anticipated that personalized recreational activities can improve both quality of life and behavior. To test this hypothesis, they measured affect and behavior while 30 behaviorally symptomatic nursing home residents participated in repeated 20-minute recreational activities suited to: (i) their former interests; (ii) their current skill levels, and (iii) a combination of interests and skills. Blinded observers watched videotapes of sessions and rated the intensity and duration of participants' behaviors. All treatment conditions worked better than baseline in reducing agitation $(\mathrm{p}<0.01)$ but none proved superior to another.

Validation therapy seeks to engage dementia sufferers in a warm, empathic interaction. Toseland et al. (1997) randomly assigned 88 nursing home residents to either four 30-minute validation group sessions each week for a year, or to "social contact" groups, or usual care. A quarter of participants failed to complete this lengthy trial. Validation sessions were relatively structured with a greeting, hand holding, singing, reminiscence and refreshments. Session leaders aimed to respond to participants' implicit communications by means of simple, concrete words spoken in clear, low tones. Social contact groups, by contrast, followed a manual of standard activities for people with dementia. Contrary to expectations, objective measures of agitated behaviors were actually lower at 3and 12-month reviews in the social contact group $(\mathrm{p}<0.01)$.

Progressive muscle relaxation training was tested as a treatment of agitation in an RCT with 34 community-resident dementia sufferers and their carers (Suhr et al., 1999). Muscle relaxation was selected because it relies on procedural (or motor) memory which is better preserved in Alzheimer's disease than verbal memory. To test its effectiveness, weekly muscle relaxation training sessions were compared with an individualized imaginal relaxation technique that relied more on verbal skills. At two-month follow-up, scores on the Behavior Rating in Alzheimer's Disease Scale fell in both groups with no significant difference between them.

\section{Discussion}

Most previous systematic reviews of psychosocial treatments applied limited, if any, quality standards when selecting articles (Cohen-Mansfield, 2001; Snowden et al., 2003; Bharani and Snowden, 2005; Livingston et al., 2005; Turner, 2005; Landreville et al., 2006).

Three reviews adopted a more discriminating approach, though not as rigorous as ours. Ayalon et al. (2006), in a review of three RCTs and six RM studies, found evidence in favor of fitting hearing aids, caregiver education, behavioral interventions and bright light therapy. Spira and Edelstein (2006), in a review of 23 articles including clinical case series, also deduced evidence in support of behavioral approaches while Verkaik et al. (2005) were not convinced of the value of most psychosocial remedies, with the exception perhaps of activity programs as a treatment of aggression.

We chose an even more focused approach to address three questions: Are the benefits of psychosocial treatments in reducing the frequency and/or severity of agitated behaviors just the result of the non-specific care and attention implicit in any research project? Are these changes in behavior clinically relevant? And how does one treatment compare with another? This entailed selecting papers that met relatively rigorous methodological criteria, while making allowance for the difficulties that bedevil behavioral research (limited funding, small sample sizes, variable clinical presentations and a lack of blinding to treatment conditions). A need for rigor was tempered, therefore, by an appreciation of the obstacles facing investigators.

Only 25 of 118 relevant published reports met all the selection criteria, mostly through lack of an adequate control for the attention, stimulation and diversion that follow almost invariably from participation in a study. Selecting papers in this way reduces the likelihood that positive findings are due just to placebo effects, regression to the mean, experimental bias or statistical error.

Research standards are rising nonetheless. When Opie et al. (1999) applied the same quality scale as the one used here to the 43 "best quality" papers available at that time, half were rated as "weak." In contrast, most of the studies considered here were relatively robust with clear inclusion criteria; detailed accounts of methods and participants; structured behavioral observations, and proven inter-rater reliability. Only three were graded as "weak," in two cases because follow-up periods were ambitiously long and large numbers of participants dropped out.

Since empathic, attentive human interaction reduces anxiety and agitation, it is hardly surprising that psychosocial treatments proved no more effective than attention control conditions in 11 of 23 studies (the two others compared one treatment with another). Real differences in outcome might 
have been missed on occasions if small numbers of participants resulted in low statistical power. The mean number of participants in the 13 "failed" studies was 54 (range 20-127), a modest figure in contrast to most drug trials. One solution is for researchers to standardize reporting details (e.g. mean behavior counts per observation session) so that results can be pooled later. This is not possible at present. Study designs, eligibility criteria and behavior measures vary too widely to permit numeric meta-analysis.

One limitation to our review is that we considered only objective changes in agitated behaviors, or the consequences of behaviors. Outcomes not addressed here (e.g. physical activity, nutrition, comfort, social connectedness and quality of life) also have value. Ballard et al. (2002), for example, noted improvements in social engagement and constructive activity with the use of aroma while Sherratt et al. (2004) reported heightened wellbeing with live music. People with dementia are more than the sum of their behaviors and clinicians might well persist with an empirically unproven activity if it is enjoyable, healthy and culturally appropriate. Carers' views must also be considered. Nursing home staff and relatives enjoyed the pictures, aromas and sounds provided by CohenMansfield and Werner (1998) and family carers benefited along with study participants from the relaxation training provided by Suhr et al. (1999).

\section{Treatments}

Aromatherapy, which barely figured in earlier reviews, looks promising. Lavender reduced the frequency of agitation more than water vapor (Holmes et al., 2002) and massage with lemon balm worked better than sunflower oil (Ballard et al., 2002). It is unlikely that these benefits stemmed just from exposure to pleasant smells since dementia blunts olfaction. There is increasing evidence that the volatile constituents in essential oils cross the blood-brain barrier and bind to relevant neuronal receptors, at least in animals (Holmes and Ballard, 2004). Further trials of this inexpensive, pleasant, non-toxic intervention are clearly warranted.

The two bathing studies, taken together, show that efforts to make this essential routine more palatable to people with dementia, and safer for caregivers, are worthwhile. While bed baths proved no more effective than person-centered showering in reducing agitation and aggression, they were clearly more comfortable for residents (Sloane et al., 2004) and ensured greater privacy. Staff resistance is likely to be high due to fears of inefficiency and inadequate hygiene and further studies will be required to check that bed baths are genuinely efficient and effective in a wider range of settings. As an aside, bath times provide an excellent paradigm for pharmacological and psychosocial research given their association with peak levels of disturbed behaviors (Burgener et al., 1992). Concerns regarding participants' privacy can be allayed through the use of nurse-researchers whose presence in the bathroom is warranted clinically.

We expected to find that boosting carers' knowledge, empathy and communication skills would lead to significant falls in agitation and aggression. While there were trends in this direction (Wells et al., 2000; Gormley et al., 2001; Sloane et al., 2004), the outcomes were not striking. In the largest study, Teri et al. (2000) compared two medications, an antipsychotic and an antidepressant, with a family behavior management training program. None worked better than a placebo tablet. Two other studies followed nursing home residents over a six-month period (Wells et al., 2000; Burgio et al., 2002). Staff members' skills were enhanced, and residents in the latter study were a little calmer and functioned more independently, but levels of agitation were barely altered. A six-month interval is possibly too long. As dementia progresses, disturbed behaviors remit spontaneously and lengthy studies might therefore fail to capture real shifts in behavior over shorter periods. Training programs can certainly change family and professional caregivers' attitudes, knowledge and skills and are valuable for this reason (Burgio et al., 2002; Brodaty et al., 2003). What impact they have on behavior over a shorter time frame remains to be seen.

Multi-sensory stimulation comes from the field of learning disability, as a means to enrich and stimulate the worlds of profoundly disabled people. Neither of the two studies reviewed here proved effective overall for people with dementia, though some participants responded well (Baillon et al., 2004). Random lights, sounds and shapes might prove disturbing for some confused, disoriented older people. Efforts by Cohen-Mansfield and Werner (1998) to remedy bleak, impoverished nursing home surrounds found favor with staff and visitors but had a limited effect on residents' wandering and exit-seeking behavior.

Music proved very effective in five out of eight studies. Agitated behaviors responded better to individually tailored music than "classical relaxation music" (Gerdner, 2000) and aggression declined significantly when participants' preferred music was played during bath times (Thomas et al., 1997; Clark et al., 1998). "Off the shelf" music, by contrast, worked no better than hand massage (Remington et al., 2002), book readings (Groene, 1993) or mealtimes without music (Ragneskog 
et al., 1996). Tailoring music to individuals' preferences is clearly important. Live, as opposed to pre-recorded, music had the additional benefit of promoting arousal and social engagement (Sherratt et al., 2004).

Simulated presence tapes, which employ technology to create the illusion of family intimacy, are effective, though Garland et al. (2007) found that relatives, many of whom felt very unhappy and guilty, became distressed when asked to recount happy memories from the past. This emotive component is probably not critical as tapes worked just as well when relatives chose their own material (Cohen-Mansfield and Werner, 1997). Personalized music audiotapes reduced agitation levels almost as well as simulated family presence tapes and one-to-one social interaction in a multi-treatment study by Cohen-Mansfield and Werner (1997) and are relatively cheap and easy to prepare. Social interaction tailored to participants' interests and aptitudes worked best of all, however. Confused nursing home residents who live with people they fail to recognize, for reasons they cannot comprehend, respond well to personal care and attention. Unfortunately, this "treatment" is the one in shortest supply in most aged care facilities in which staff are busy, stressed and poorly remunerated.

We reviewed only single studies of recreation, relaxation and validation therapy. Personalized recreational activities worked better than usual care but, in contrast to music, attention to participants' skills and interests produced little extra benefit (Kolanowski et al., 2005). Validation therapy proved inferior to social contact groups (Toseland et al., 1997), pointing again to the value of one-to-one, attentive interaction. Progressive muscle relaxation proved useful both to patients and carers.

\section{Conclusions}

Aromatherapy, bed baths, person-centered bathing, preferred music, one-to-one social interaction, simulated family presence and muscle relaxation therapy all reduced behavioral symptoms better than control conditions. Evidence is particularly strong for aroma (Ballard et al., 2002), bed baths (Dunn et al., 2002), gentle sounds (Burgio et al., 1996), individualized music (Gerdner, 2000) and muscle relaxation training (Suhr et al., 1999). All five treatments are supported by studies with robust designs (RCTs or RXTs), that rated as "moderate" or "strong" on the Forbes quality scale and had moderate or high statistical precision $(\mathrm{p}<0.01)$.

Evidence checklists like those devised by the Australian National Health and Medical Research
Council (NH\&MRC, 2000b) attach greatest value to RCTs (Level 2) and downplay the role of "before and after" RM studies (Level 4). Using NH\&MRC rules, only the RCT of relaxation training (Suhr et al., 1999) was rated as 2 . The other "best" studies achieved ratings of only 3 a (Ballard et al., 2002) and 4 (Burgio et al., 1996; Gerdner, 2000; Dunn et al., 2002). These scores are too low in our opinion for the reasons outlined above (see Methods). There is therefore sufficient evidence to support the use of aroma, bed baths, gentle sounds, individualized music and muscle relaxation training as treatments of behavioral symptoms.

This is not to say that other treatments are ineffective. It means only that their benefits cannot be attributed confidently to a unique therapeutic modality. Most treatments entailed some measure of human contact, either directly or indirectly. Positive interaction between the person with dementia on the one hand, and a family member or care attendant on the other, might form the common basis of many of these interventions.

This is not a weakness. Human contact can be conceptualized as a treatment of agitation, not just an attention control, that is worthy of study in its own right. In an important study by Cohen-Mansfield and Werner (1997), nursing home residents responded even better to carefully crafted, one-toone social interaction than to two "established" interventions, namely individualized music and simulated family presence. Further scrutiny is warranted to establish the necessary components of personal interaction, optimal activities, time frames and cultural nuances. Given the shortage of staff in most aged care facilities, and the focus on nursing procedures, one option is to train and support willing family members and volunteers as therapy facilitators.

With respect to treatment duration, CohenMansfield and Werner (1997) noted that two of their 32 severely impaired nursing home residents resumed speaking after a couple of sessions of individually tailored one-to-one interaction but the benefits of psychosocial treatments were otherwise short-lived in the few studies that addressed this (Gerdner, 2000; Garland et al., 2007). This is not a problem, though, if the object is to settle or prevent symptoms that arise in specific situations (e.g. aggression during bathing). Short-term problems might respond quite adequately to short-term solutions.

Marked differences in treatment responses were noted by several investigators. While some participants benefited from an intervention, a few became more agitated (e.g. Camberg et al., 1999; Baillon et al., 2004; Garland et al., 2007). If analyses are based solely on measures of central tendency 
and dispersion, as usually happens now, important within-group differences will not be recognized and a treatment that benefits just a proportion of people, who perhaps share certain characteristics, will be rated a failure. One solution is to list the proportions of study participants whose symptoms improve or worsen to a specified degree. For example Garland et al. (2007), in their comparison of simulated family presence and preferred music, found that behavior counts fell by $50 \%$ or more in both treatment arms, despite unimpressive results overall. An unspecified proportion of people became more disturbed. These additional details add a useful perspective and should be encouraged. A simple, cheap treatment that unsettles some participants can be stopped quickly when indicated, with no long-term sequelae.

Treatments tailored to individuals' backgrounds and preferences, whether in the form of music, activity or conversation, seem especially beneficial (Cohen-Mansfield and Werner, 1997; Thomas et al, 1997; Clark et al., 1998; Gerdner, 2000; Sherratt et al., 2004; Garland et al. 2007). This point has emerged strongly in other reviews too (Opie et al., 1999; Cohen-Mansfield, 2001; Livingston et al., 2005) and it should guide further research in this area. Interventions might also be tailored usefully to participants' symptoms or symptom profiles. Cohen-Mansfield and Werner (1997), for example, found that verbal disruption due to hallucinations responded best to simulated family presence while requests for attention benefited most from one-toone attention. Fine-grained research is required to address these complex issues.

From a methodological perspective, advances in this field of research will include: (i) a requirement that study participants demonstrate one or more behavioral symptoms, to a specified degree and for a specified time, (ii) deploying treatments in time frames and settings (e.g. bath times) when symptoms are most evident, (iii) reporting refusal rates and drop-outs, (iv) tailoring treatments where practicable to participants' backgrounds and interests; (v) reporting multiple outcomes for participants (e.g. behavior, activity, mood) as well as caregivers (e.g. preferences, time savings); and (vi) outlining treatment costs, convenience and poststudy take-up rates. Most investigators now measure behaviors directly rather than relying on informant reports which have lower inter-rater reliability (Cohen-Mansfield, 1996). Time-sampling makes it possible to monitor several subjects' behaviors simultaneously. Behaviors can also be videotaped and analyzed later. These methods work less well with low frequency behaviors.

It is clear that behavioral symptoms are difficult to treat, irrespective of approach, and that nonspecific placebo effects explain a proportion of the benefits seen. This applies just as much to pharmacological treatments as psychosocial ones. In a meta-analysis by Schneider (1996), antipsychotics proved only $18 \%$ more effective than placebo tablets which alone were associated with an average percentage improvement of $37 \%$. While a meta-analysis of risperidone showed it to be effective (De Deyn et al., 2005), a recent large RCT of three atypical antipsychotics in "real world" conditions proved disappointing (Schneider et al., 2006). Even combinations of carefully tailored nursing, psychosocial and medical interventions resulted in relatively modest, though statistically significant, changes in behavior in a nursing trial by Opie et al. (2002) in which counts of restlessness and verbal disruption fell by $26 \%$ and $20 \%$ respectively. Much of this improvement was evident before treatments actually started.

Seen in this context, aroma and music seem attractive interventions given their evidence base, ease of application and low cost. Their effects are probably relatively short-lived but this might prove adequate for some behaviors in certain situations. The task for clinicians and researchers is to discern and articulate these subtleties. A research strategy should therefore seek to (i) test further simple, affordable psychosocial interventions in community and residential settings; (ii) check their effectiveness at times when difficult behaviors are most evident; and (iii) define what treatment properties appeal most to family and professional caregivers.

None of the strategies considered here qualifies in most countries for government or insurance rebates. Time and expense are therefore important considerations. A simple treatment might succeed where an elaborate one fails. Nursing home staff must also be persuaded that a treatment is worthwhile. They are more likely to persist with an intuitively attractive intervention that is pleasant for staff and residents and confers demonstrable benefits in high risk situations. The challenge is to identify treatments that meet all these requirements.

\section{Conflict of interest}

Because the Editor of International Psychogeriatics is a co-author, this paper was independently reviewed at arm's-length under the supervision of the Deputy-Editor.

\section{Description of authors' roles}

Daniel O'Connor devised the review, selected and condensed material, and wrote the paper with support from David Ames. Betina Gardner checked 
material and co-rated papers. Madeleine King computed effect sizes.

\section{Acknowledgments}

This review was funded by the Dementia Collaborative Research Centre under the Australian Commonwealth Government's "Dementia: A National Health Priority" initiative. We thank Professors Henry Brodaty and Jiska Cohen-Mansfield for helpful comments on an earlier draft of this paper.

\section{References}

Altman, D. G., Schulz, K. F., Moher, D., Egger, M. and Davidoff, F. (2001). The revised CONSORT statement for reporting randomised trials: explanation and elaboration. Annals of Internal Medicine, 134, 663-694.

Ayalon, L., Gum, A. M., Feliciano, L. and Arean, P. A. (2006). Effectiveness of nonpharmacological interventions for the management of neuropsychiatric symptoms in patients with dementia. Archives of Internal Medicine, 166, 2182-2188.

Baillon, S., Van Diepen, E., Prettyman, R., Redman, J., Rooke, N. and Campbell, R. (2004). A comparison of the effects of Snoezelen and reminiscence therapy on the agitated behaviour of patients with dementia. International Fournal of Geriatric Psychiatry, 19, 1047-1052.

Baker, R. et al. (2003). Effects of multi-sensory stimulation for people with dementia. Fournal of Advanced Nursing, 43, 465-477.

Ballard, C. G., O'Brien, J. T., Reichelt, K. and Perry, E. K. (2002). Aromatherapy as a safe and effective treatment for the management of agitation in severe dementia: the results of a double-blind, placebo-controlled trial with Melissa. Fournal of Clinical Psychiatry, 63, 553-558.

Bharani, N. and Snowden, M. (2005). Evidence-based interventions for nursing home residents with dementia-related behavioral symptoms. Psychiatric Clinics of North America, 28, 985-1005.

Brodaty, H., Green, A. and Koschera, A. (2003). Meta-analysis of psychosocial interventions for caregivers of people with dementia. Fournal of the American Geriatrics Society, 51, 657-664.

Burgener, S. C., Jirovec, M., Murrell, L. and Barton, D. (1992). Caregiver and environmental variables related to difficult behaviors in institutionalized, demented elderly persons. Fournal of Gerontology, 47, P242-249.

Burgio, L., Scilley, K., Hardin, J. M., Hsu, C. and Yancey, J. (1996). Environmental "white noise": an intervention for verbally agitated nursing home residents. Fournal of Gerontology, 51, P364-373.

Burgio, L. D., Stevens, A., Burgio, K. L., Roth, D. L., Paul, P. and Gerstle, J. (2002). Teaching and maintaining behavior management skills in the nursing home. Gerontologist, 42, 487-496.

Camberg, L. et al. (1999). Evaluation of simulated presence: a personalized approach to enhance well-being in persons with Alzheimer's disease. Fournal of the American Geriatrics Society, 47, 446-452.

Clark, M. E., Lipe, A. W. and Bilbrey, M. (1998). Use of music to decrease aggressive behaviors in people with dementia. Fournal of Gerontological Nursing, 24 (7), 10-17.

Cohen, J. (1988). Statistical Power Analysis for the Behavioral Sciences (2nd edn). Hillsdale, NJ: Lawrence Earlbaum.

Cohen-Mansfield, J. (1986). Agitated behaviours in the elderly II: preliminary results in the cognitively deteriorated. Fournal of the American Geriatrics Society, 34, 722-727.

Cohen-Mansfield, J. (1996). Behavioral and mood evaluations: assessment of agitation. International Psychogeriatrics, 8, 233-245.

Cohen-Mansfield, J. (2001). Nonpharmacologic interventions for inappropriate behaviors in dementia: a review, summary, and critique. American fournal of Geriatric Psychiatry, 9, 361-381.

Cohen-Mansfield, J. and Werner, P. (1997). Management of verbally disruptive behaviours in nursing home residents. fournal of Gerontology, 52A, M369-377.

Cohen-Mansfield, J. and Werner, P. (1998). The effects of an enhanced environment on nursing home residents who pace. Gerontologist, 38, 199-208.

De Deyn, P. P., Katz, I. R., Brodaty, H., Lyons, B., Greenspan, A. and Burns, A. (2005). Management of agitation, aggression and psychosis associated with dementia: a pooled analysis including three randomized, placebo-controlled double-blind trials in nursing home residents treated with risperidone. Clinical Neurology and Neurosurgery, 107, 497-508.

Dunn, J. C., Thiru-Chelvam, B. and Beck, C. H. M. (2002). Bathing: pleasure or pain? fournal of Gerontological Nursing, 28 (11), 6-13.

Forbes, D. A. (1998). Strategies for managing behavioural symptomatology associated with dementia of the Alzheimer type: a systematic overview. Canadian fournal of Nursing Research, 30, 67-86.

Garland, K., Beer, E., Eppingstall, B. and O'Connor, D. W. (2007). A comparison of two treatments of agitated behavior in nursing home residents with dementia: simulated presence and preferred music. American fournal of Geriatric Psychiatry, 15, 514-521.

Gerdner, L. A. (2000). Effects of individualized versus classical "relaxation" music on the frequency of agitation in elderly persons with Alzheimer's disease and related disorders. International Psychogeriatrics, 12, 49-65.

Gormley, N., Lyons, D. and Howard, R. (2001). Behavioural management of aggression in dementia: a randomized controlled trial. Age and Ageing, 30, 141-145.

Greve, M. and O'Connor, D. (2005). A survey of Australian and New Zealand old age psychiatrists' preferred medications to treat behavioral and psychological symptoms of dementia. International Psychogeriatrics, 17, 165-178.

Groene, R. W. (1993). Effectiveness of music therapy 1:1 intervention with individuals having senile dementia of the Alzheimer's type. Fournal of Music Therapy, 30, 138-157.

Hall, G. R. and Buckwalter, K. C. (1987). Progressively lowered stress threshold: a conceptual model for care of adults with Alzheimer's disease. Archives of Psychiatric Nursing, 1, 399-406. 
Haupt, M. and Kurz, A. (1993). Predictors of nursing home placement in patients with Alzheimer's disease. International fournal of Geriatric Psychiatry, 8, 741-746.

Holmes, C. and Ballard, C. (2004). Aromatherapy in dementia. Advances in Psychiatric Treatment, 10, 296-300.

Holmes, C., Hopkins, V., Hensford, C., MacLaughlin, V., Wilkinson, D. and Rosenvinge, H. (2002). Lavender oil as a treatment for agitated behaviour in severe dementia: a placebo controlled study. International fournal of Geriatric Psychiatry, 17, 305-308.

Kolanowski, A. M., Litaker, M. and Buettner, L. (2005). Efficacy of theory-based activities for behavioral symptoms of dementia. Nursing Research, 54, 219-228.

Landreville, P. et al. (2006). Non-pharmacological interventions for aggressive behavior in older adults living in long-term care facilities. International Psychogeriatrics, $18,47-73$.

Livingston, G., Johnston, K., Katona, K., Paton, J. and Lyketsos, C. G. (2005). Systematic review of psychological approaches to the management of neuropsychiatric symptoms of dementia. American fournal of Psychiatry, 162, 1996-2021.

NH\&MRC (2000a). How to review the evidence: systematic identification and review of the scientific literature. Canberra: National Health and Medical Research Council.

NH\&MRC (2000b). How to use the evidence: assessment and application of scientific evidence. Canberra: National Health and Medical Research Council.

O'Connor, D. W., Pollitt, P. A., Roth, M., Brook, C. P. B. and Reiss, B. B. (1990). Problems reported by relatives in a community study of dementia. British fournal of Psychiatry, 156, 835-841.

Opie, J., Rosewarne, R. and O'Connor, D. W. (1999). The efficacy of psychosocial approaches to behaviour disorders in dementia: a systematic literature review. Australian and New Zealand Fournal of Psychiatry, 33, 789-799.

Opie, J., Doyle, C. and O'Connor, D. W. (2002). Challenging behaviours in nursing home residents with dementia: a randomized controlled trial of multidisciplinary interventions. International fournal of Geriatric Psychiatry, 17, 6-13.

Ragneskog, H., Bråne, G., Karlsson, I. and Kihlgren, M. (1996). Influence of dinner music on food intake and symptoms common in dementia. Scandinavian fournal of Caring Sciences, 10, 11-17.

Remington, R. (2002). Calming music and hand massage with agitated elderly. Nursing Research, 51, 317-323.

Rosnow, R. L. and Rosenthal, R. (1996). Computing contrasts, effect sizes, and counternulls on other people's published data: general procedures for research consumers. Psychological Methods, 1, 331-340.

Schneider, L. S. et al. (1996). Meta-analysis of controlled pharmacologic trials. International Psychogeriatrics, 8 (Suppl. 3), 375-379.
Schneider, L. S. et al. (2006). Effectiveness of atypical antipsychotic drugs in patients with Alzheimer's disease. New England fournal of Medicine, 355, 1525-1538.

Sherratt, K., Thornton, A. and Hatton, C. (2004). Emotional and behavioural responses to music in people with dementia: an observational study. Aging and Mental Health, 8, 233-241.

Sink, K. M., Holden, K. F. and Yaffe, K. (2005). Pharmacological treatment of neuropsychiatric symptoms of dementia: a review of the evidence. $7 A M A, 293,596-608$.

Sloane, P. D. et al. (2004). Effect of person-centred showering and the towel bath on bathing-associated aggression, agitation, and discomfort in nursing home residents with dementia: a randomized, controlled trial. Fournal of the American Geriatrics Society, 52, 1795-1804.

Snowden, M., Sato, K. and Roy-Byrne, P. (2003). Assessment and treatment of nursing home residents with depression or behavioral symptoms associated with dementia: a review of the literature. Fournal of the American Geriatrics Society, 51, 1305-1317.

Spira, A. P. and Edelstein, B. A. (2006). Behavioral interventions for agitation in older adults with dementia: an evaluative review. International Psychogeriatrics, 18, 195-225.

Suhr, J., Anderson, S. and Tranel, D. (1999). Progressive muscle relaxation in the management of behavioural disturbance in Alzheimer's disease. Neuropsychological Rehabilitation, 9, 31-44.

Teri, L. et al. (1998). Treatment for agitation in dementia patients: a behavior management approach. Psychotherapy, 35, 436-443.

Teri, L. et al. (2000). Treatment of agitation in AD: a randomized, placebo-controlled clinical trial. Neurology, 55, 1271-1278.

Thomas, D. W., Heitman, R. J. and Alexander, T. (1997). The effects of music on bathing cooperation for residents with dementia. Fournal of Music Therapy, 34, 246-259.

Toseland, R. W., Dieh1, M., Freeman, K., Manzanares, T., Naleppa, M. and McCallion, P. (1997). The impact of validation group therapy on nursing home residents with dementia. Fournal of Applied Gerontology, 16, 31-50.

Turner, S. (2004). Behavioural symptoms of dementia in residential settings: a selective review of non-pharmacological interventions. Aging and Mental Health, 9, 93-104.

Verkaik, R, Van Weert, J. C. M. and Francke, A. L. (2005). The effects of psychosocial methods on depressed, aggressive and apathetic behaviors of people with dementia: a systematic review. International fournal of Geriatric Psychiatry, 20, 301-314.

Wells, D. L., Dawson, P., Sidani, S., Craig, D. and Pringle, D. (2000). Effects of an abilities-focused program of morning care on residents who have dementia and on caregivers. Fournal of the American Geriatrics Society, 48, 442-449. 